\title{
Desenvolvimento comunitário na formação do nutricionista: relato de experiência em um Curso de Nutrição
}

\author{
Community development in the dietician \\ training: Reports of experiences from \\ a nutrition course
}

Nilce de OLIVEIRA ${ }^{1}$

Sandra Maria Chaves dos SANTOS

RE S U M O

\section{Objetivo}

Este trabalho tem como objetivo discutir a disciplina Desenvolvimento da Comunidade no currículo do curso de Nutrição de uma universidade pública, visando contribuir com o debate sobre a formação social do nutricionista.

\section{Métodos}

Trata-se de pesquisa documental, com base no material da disciplina e nos trabalhos produzidos pelos alunos ao longo de 30 anos de docência, além de reflexão sobre as experiências vividas.

\section{Resultados}

Apesar da recorrente afirmação da relevância do tratamento social em saúde e nutrição, ainda é insatisfatória a introdução dos componentes que poderiam construir esse processo. Desde sempre, o trabalho prático manifestou-se sedutor e revelador da realidade social e econômica para os estudantes, enquanto a compreensão teórica dos processos e relações sociais resulta problemática e recebe a justificativa de que, para os alunos da área de saúde, a linguagem das Ciências Sociais seria estranha e difícil.

\section{Conclusão}

A experiência docente na disciplina Desenvolvimento da Comunidade confirma a importância da abordagem teórica e prática da saúde, alimentação e nutrição pelas Ciências Sociais, significando um esforço pedagógico e pessoal a mais do professor e de alunos. Mesmo que a disciplina deixe de existir na formação do nutricionista com o título original, que faz parte do repertório semântico de um tempo passado, os conteúdos e as experiências permanecem sendo relevantes e podem ser incorporadas em outras disciplinas.

Termos de indexação: Ciências Sociais. Desenvolvimento da comunidade. Ensino. Nutricionista.

1 Universidade Federal da Bahia, Escola de Nutrição, Departamento da Ciência da Nutrição. Av. Araújo Pinho, 32, Canela, 40110-150, Salvador, BA, Brasil. Correspondência para/Correspondence to: N OLIVEIRA. E-mail: <nilce@ufba.br>. 


\section{A B S T R A C T}

\section{Objective}

The article discusses the development of the discipline called Community Development within the curriculum of a nutrition program at a public university to contribute to the debate on dieticians' social education.

\section{Methods}

This is a document research, based on the discipline material, as well as the works produced by students throughout the 30 years of administration of the discipline and also reflections on lived experiences.

\section{Results}

Despite the applicants' reaffirmation on the importance of social-oriented health and nutrition practices, there is still an unsatisfactory introduction of academic components that would help to build this process. While empirical works always appeared as a seductive way for students to understand the social and economic reality of the city, theoretical understanding of processes and social relationships showed to be problematic, which is being explained by the fact that social sciences language is strange and difficult in the eyes of health students.

\section{Conclusions}

Experience in Community Development confirms the importance of theoretical and practical approach of Health, Food and Nutrition by the Social Sciences, signifying a pedagogical and personal effort of teachers and students. We conclude that even if the Community Development discipline ceases to exist in the training of dieticians with the original title, which is part of the semantic repertoire of a past time, content and experiences remain relevant and can be incorporated into other disciplines.

Indexing terms: Social Sciences. Community development. Teaching. Dietician.

\section{N T R O D U ÇÃ O}

A necessidade da abordagem social na formação dos profissionais de saúde tem sido muito discutida no espaço acadêmico. Na Nutrição destacam-se os antecedentes inspiradores dos debates ocorridos na América Latina, tanto na Conferência de Caracas (1966), sob a organização do Instituto de Nutrición de Centro América y Panamá (INCAP), quanto na Comissão de Estudos e Programas Acadêmicos de Nutrição e Dietética na América Latina (Cepandal), criada em 1973, com seus desdobramentos no Brasil' ${ }^{1}$. Esses debates constituíram marcos na concepção da formação do nutricionista a partir da década de 1970, mobilizando os cursos de Nutrição brasileiros, cujas proposições conferiam uma maior importância às Ciências Sociais e Econômicas bem como à Educação e Saúde Pública, contrapondo-se à excessiva ênfase nos conteúdos das Ciências Naturais. Nesse contexto foi criada a disciplina Desenvolvimento da Comunidade como componente do Currículo Mínimo para a formação de nutricionistas no País.
$\mathrm{Na}$ literatura sociológica o desenvolvimento da comunidade é entendido como: processo social, político e educativo da própria sociedade civil em defesa da comunidade; política social, com programas intersetoriais integrados de intervenção na comunidade; metodologia para a intervenção social, sempre com presença externa de agentes públicos ou voluntários; e, ainda, como resultado de qualquer desses processos, expresso em melhorias físicas com dotação de infraestrutura, equipamentos, saneamento ou serviços sociais, sejam estes de caráter educacional, qualificação profissional ou geração de renda e saúde, entre outros ${ }^{2,3}$.

Bosi ${ }^{4}$ constatou, no entanto, que os cursos continuavam sob o domínio do paradigma biomédico, inaugurado quando do surgimento da nutrição como profissão no Brasil. Tais cursos nasceram e prosperaram no âmbito hospitalar, apesar da contribuição das políticas públicas de alimentação e combate à fome, possível campo do exercício do novo profissional, políticas cuja expressão apareceu nos anos 1940 1,5. 
A saúde pública, a prevenção de doenças e a promoção da saúde tiveram, a partir dos anos 1980, forte presença nas discussões sobre a formação dos profissionais de saúde, aliadas à compreensão da importância do conhecimento da realidade social para compreensão do quadro epidemiológico e do processo saúde-doença. Especialmente para os nutricionistas, os temas da fome e da desnutrição (anos 1970 e 1980) reforçavam a necessidade do conhecimento e da interpretação dos problemas sociais à luz das Ciências Sociais, Políticas e Econômicas.

Apesar do reconhecimento da importância do tema nas avaliações dos cursos e nos debates sobre a formação do profissional, essa área do conhecimento ainda não havia alcançado o mesmo estatuto dos conhecimentos biológicos na maioria dos projetos pedagógicos quando da aprovação das Diretrizes Curriculares de $2001^{6}$ Soares \& Aguiar ${ }^{7}$ analisaram que problemas relativos ao diálogo social-biológico na formação do nutricionista persistem, por exemplo, no estudo dos alimentos e da dinâmica da cadeia alimentar produtiva, devido à falta de abordagem dos fatores históricos, culturais, sociais, políticos, econômicos e ambientais envolvidos.

O curso de Nutrição em foco mantém sua estrutura curricular básica de 1979. Entretanto, tem passado por algumas adequações visando acompanhar os avanços do conhecimento e as mudanças sociais, especialmente aquelas que afetam a alimentação e a saúde, tais como: ajustes e aumento de carga horária total e especialmente dos conteúdos práticos; flexibilização do sistema de pré-requisitos; ampliação da oferta de disciplinas optativas, sempre na linha profissionalizante e de aprofundamento específico, bem como na cobertura de áreas ainda inexploradas, como Nutrição e Atividade Física, Aspectos Socioculturais da Alimentação; e inclusão do Trabalho de Conclusão de Curso.

O percurso da disciplina Desenvolvimento da Comunidade (DC) foi discutido visando contribuir para o debate sobre a formação social do nutricionista, residindo aí o recorte deste artigo.
Isso se faz aqui a partir de pesquisa documental, com base no material didático da disciplina e nos trabalhos produzidos pelos alunos ao longo de 30 anos de docência, além de reflexão sobre as experiências vividas.

\section{Histórico da disciplina Desenvolvimento da Comunidade no currículo do curso}

Em 1982, a disciplina DC foi iniciada para os alunos regidos pelo currículo de 1979. Após rejeição pelo Departamento de Sociologia, que a qualificou como pertencente ao campo do Serviço Social, a disciplina foi incluída no Departamento de Ciência da Nutrição, tendo uma docente socióloga para ministrá-la dentro da própria escola, o que a distingue de outras disciplinas sociais do Ciclo Básico que não são específicas para o curso de Nutrição, justificativa do foco desta análise.

Para implantação da disciplina, a ementa era o único elemento da nova proposta curricular a elucidar o campo temático. Nela se concretizava a ideia de que a comunidade poderia contribuir para a melhoria do estado nutricional por meio da ação comunitária e da participação nos programas sociais de saúde e alimentação. A disciplina se pretendia instrumental, preparando o nutricionista para se tornar um agente técnico da ação comunitária, seja em programas de nutrição aplicada, seja integrando equipes de saúde pública.

O primeiro programa da disciplina, de 45 horas, continha três unidades: 1) Aspectos conceituais e realidade brasileira; 2) Desenvolvimento de Comunidade como técnica de trabalho social; 3) Programas de Ação Comunitária. Para a primeira unidade, eminentemente sociológica, planejou-se a integração com o pré-requisito Introdução à Sociologia. Tal integração, continuamente buscada, teve resultado pouco eficaz por um conjunto de razões, a destacar a mudança constante dos professores de Sociologia, que preferem atuar no curso de Ciências Sociais, e o princípio da Reforma Universitária de 1968, com turmas de alunos oriundos de diversos cursos e áreas, 
com prejuízo para a identificação profissional com o tema.

A disciplina Desenvolvimento da Comunidade está em constante atualização, enfatizando no conteúdo: as condições de vida da população brasileira, com destaque para a pobreza, as desigualdades de classes e regionais, a exclusão e as iniquidades sociais e econômicas persistentes; a conjuntura social e política e, especialmente, os movimentos populares. A disciplina se constituiu num observatório da realidade social brasileira, do quadro político, do processo democrático, da organização partidária e sindical, dos movimentos sociais e das políticas sociais, numa perspectiva crítica.

Após três anos de experimentação, em 1985, ocorreu a primeira adequação curricular, liderada pela coordenação do curso. Foram superpostas as disciplinas Desenvolvimento da Comunidade e Desenvolvimento da Comunicação, criando-se a nova disciplina Desenvolvimento da Comunidade e da Comunicação (DCC), com 60 horas. Com isso foram reduzidas 30 horas de conteúdo no campo das Ciências Sociais, redistribuídas entre disciplinas profissionalizantes, denotando que os conteúdos sociais permaneciam sendo considerados secundários. A tônica da alteração foi a criação de turmas teóricas e práticas, estas últimas com módulos reduzidos, segundo os locais de prática: serviços de saúde, laboratórios e outros campos - caso de DCC, cujas turmas práticas ficaram com 15 alunos.

Houve então a incorporação da unidade Comunicação Comunitária, a qual foi integrada a partir de parceria produtiva entre o responsável pelo componente comunitário e o professor de Comunicação, o qual aportou elementos sobre o processo de comunicação. Durante a parceria iniciada em 1986, o professor de Comunicação elegeu como recurso didático a projeção de filmes de curta metragem, seguida de debate e complementação com exposições temáticas, leitura complementar, cabendo aos estudantes elaborar uma resenha sobre o filme. Os filmes exibidos durante a experiência apresentavam forte conteúdo social: problemática habitacional da população de baixa renda nas metrópoles brasileiras, trabalho infantil, migração rural-urbana, comunicação de massa e seus impactos culturais. Com isso houve maior receptividade dos conteúdos por parte dos alunos.

O programa de atividades práticas, em equipes, objetivaram inserir os estudantes em trabalhos comunitários executados por distintas instituições, através de observação, entrevistas aos agentes, líderes comunitários e beneficiários, além da análise da documentação das instituições, elaborando-se um relatório calcado na teorização sobre os temas-chave. Como exemplo, podem ser destacados trabalhos de educação comunitária coordenados por grupos humanitários ligados à Igreja e realizados em bairros muito pobres (favelas), bem como trabalhos sociopolíticos dos moradores de bairros populares, organizados em associações, em luta por infraestrutura e serviços urbanos.

Tais práticas se faziam de forma articulada com a abordagem teórica da disciplina, centrada na comunidade, no modelo brasileiro de desenvolvimento econômico e social, na realidade social brasileira e local, na teoria, história e metodologia do desenvolvimento comunitário e nas intervenções de políticas públicas e outras instituições e agentes da sociedade civil, bem como na organização de resistência da própria população no combate aos problemas sociais.

O trabalho prático na disciplina manifestou-se sedutor para os estudantes, enquanto a compreensão teórica dos processos e relações sociais resultava problemática, recebendo a justificativa de que para os alunos da área de saúde a linguagem das Ciências Sociais revelava-se estranha e difícil. O conceito de comunidade configurava-se como primeira dificuldade de compreensão dos alunos, especialmente depois da comunidade virtual que acrescentou novas incompreensões às definições dos clássicos. Selecionar uma bibliografia atrativa, substituindo capítulos de livros e artigos de sociologia básica por ensaios de ciências sociais aplicadas, menos complexos e 
de menor extensão, para conseguir um nível satisfatório de leitura mostrou-se uma dificuldade permanente.

Quanto ao campo de práticas, a década de 1980 foi rica tanto em políticas para as comunidades como em movimentos sociais, ainda que sob o regime não democrático e por esta razão. Na estrutura do poder, nos três níveis de governo, havia órgãos para execução das políticas sociais com base comunitária e meios de financiamento interno e externo, bem como órgãos de consultoria vinculados ao sistema de fomento do desenvolvimento comunitário. Efetivamente, havia uma função e uma área de trabalho voltada ao desenvolvimento da comunidade dentro do setor público, diferente do assistencialismo tradicional das instituições filantrópicas e, também, da luta dos movimentos sociais populares ${ }^{8,9}$.

Essa estrutura governamental perdurou até a primeira gestão de Fernando Henrique Cardoso, quando, a partir do Programa Comunidade Solidária, coordenado pela Socióloga Ruth Cardoso, a responsabilidade da execução de políticas sociais foi transferida para as Organizações Não-Governamentais (ONG) sob o elogio das parcerias e do novo voluntariado social ${ }^{10}$, com a responsabilização da sociedade civil por ações de interesse público. Essa configuração trouxe novas dificuldades para o acesso da universidade a campos de práticas comunitárias, na medida em que o acesso passou a ser regulado por entidades privadas. Assim, o tema da responsabilização pública ou privada da ação pública de interesse social foi tratado criticamente na disciplina.

No mesmo contexto, os projetos de DC levados a cabo pelas próprias comunidades praticamente desapareceram, porque as associações populares perderam vitalidade. Desde a redemocratização, os líderes comunitários migraram para os partidos políticos: "os líderes dos movimentos estão no poder" (p.65), disse uma líder comunitária"1.

Importante reconhecer que a proposição do componente curricular DC se deu sob o governo militar, que exercia forte papel planejador e executor da ação social, sendo um espaço tanto de busca de legitimação do governo como de oportunidade de organização e expressão de demandas comunitárias; portanto, espaço de tensões. Com a redemocratização, deu-se uma nova construção para o envolvimento comunitário, sob o discurso da participação social e/ou comunitária, a qual se daria em espaços institucionalizados, integrados por representantes da comunidade. Exemplos dessa modalidade são os conselhos criados em torno da execução de várias políticas sociais, como os conselhos municipais e locais de saúde. A disciplina DC, sem passar por alterações da ementa original, dos anos 1970, veio se adaptando aos novos cenários.

Mais recentemente, com a implantação e forte expansão de programas de transferência de renda, ocorreu o esvaziamento da política de base comunitária. Assim, avalia-se que o componente DC ficou superado em seu desenho original pela dinâmica da relação Estado-Sociedade em torno da ação social. Entretanto, proposições acadêmicas em defesa da promoção da saúde, tendo a comunidade uma participação protagonista num processo educativo, interdisciplinar e com integração dos saberes popular e científico, permanecem na agenda ${ }^{12}$.

Entende-se, portanto, que os programas sociais em curso têm concepções e metodologias que divergem dos programas de desenvolvimento comunitário. Ainda assim têm-se buscado aproximações com os programas do Sistema Único de Saúde - SUS voltados para a comunidade, as quais resultaram frustradas pelas compreensíveis dificuldades de interação entre universidade e serviços de saúde, dada a natureza diversa do processo de trabalho e dos objetivo ${ }^{13}$.

\section{A trajetória pedagógica da disciplina}

O contexto da saúde e da alimentação do brasileiro, bem como o da assistência pública (políticas, programas, serviços), se comparado com o do início dos anos 1980, mudou expressivamente. Os problemas sociais de pobreza e exclusão per- 
sistem tendo ainda uma magnitude inaceitável, apesar do aumento real do salário-mínimo nos últimos anos e dos programas de transferência de renda. Algumas situações sociais têm piorado, como é o caso da violência urbana que tanto amedronta os estudantes no trabalho de campo nos bairros populares.

A vida política teve alguns avanços com a Constituição de 1988, trazendo à baila o tema da cidadania, dos direitos humanos, da consciência e da responsabilidade social, criando novos canais de participação social, inclusive no controle de políticas públicas. No entanto, o marco legal se mostrou mais avançado que a sociedade, e o exercício consciente do compromisso e da participação plena da cidadania ainda se mostra limitado. Conforme ressaltou Milton Santos ${ }^{14}$, a declaração de intenções não teve uma tradução em ações positivas.

Tal questão também tem sido tratada com respeito aos profissionais de saúde e, por extensão, aos nutricionistas. Isso porque a atuação profissional em ações educativas e preventivas junto às comunidades pobres requer decisão política bem como recursos de infraestrutura e de logística assegurados. Além de tudo, exige consciência social e crítica do nutricionista, conforme preconizado nas Diretrizes Curriculares ${ }^{6} 0$ trabalho na área de Nutrição Social exige competência técnico-científica e também o desejo, tal como reconhece Bosi' ${ }^{15}$ analisando a relevância da satisfação no trabalho como fator de realização humana, assim como exige o compromisso com a luta política pela superação da fome e da pobreza.

\section{Estudantes de Nutrição em campo: as principais experiências}

O conhecimento da realidade social, política e econômica da população foi premissa central da disciplina, entendendo-se que ele constitui instrumento para a formação e atuação do nutricionista. Outra premissa referia-se ao essencial apoio da educação para a mudança social, na saúde e na alimentação. Assim, a educação formal e o processo de aprendizagem presente no interior dos movimentos sociais e da ação comunitária sempre tiveram espaço privilegiado no programa de DCC.

O trabalho de campo foi organizado tendo como objetivo colocar o estudante de Nutrição em contato com as necessidades da população mais pobre, preferencialmente em seu lugar de moradia, exatamente por serem poucas as oportunidades para que esse contato e aprendizagem se fizessem em condições reais de existência.

As bases metodológicas do trabalho prático e teórico pressupunham o contato com a população, suas associações e seus líderes; a observação do bairro, com a elaboração de um diário de campo; a busca de dados e informações para caracterização social, sanitária e ambiental; e o estudo dos principais problemas. A sala de aula acolhia os relatos e os debates com cidadãos engajados no processo em estudo ${ }^{16}$.

O trabalho era realizado por grupos de estudantes ao longo do semestre letivo, construído coletivamente em classe com discussão nas turmas práticas, sob orientação da docente. 0 conteúdo do relatório final contemplava a explicitação de todo o processo em contato com a comunidade e as instituições parceiras, a análise do tema e toda memória do trabalho de campo, incluindo as informações e dados levantados, além das impressões subjetivas narradas nos diários de campo. Esses relatórios constituem, portanto, a base documental da experiência aqui relatada, ao lado dos planos de curso e projetos de pesquisa e extensão agregados às atividades de ensino ${ }^{12,16,17}$.

A didática do curso nunca esteve sob o monopólio do livro nem das aulas expositivas nem dos seminários temáticos. O relato da realidade observada e os comentários críticos com interpretação dos achados do campo eram feitos pelos estudantes, com interesse. A relutância do primeiro momento face às dificuldades objetivas, de ordem logística, para o trabalho de campo desapareciam diante do forte impacto com a realidade. 
O tempo e a distância, a precariedade do transporte coletivo, a duração do deslocamento, o custo e a violência urbana cada vez mais grave se amenizavam diante do contato com os problemas sociais.

As avaliações dos estudantes demonstravam que eram alcançados os objetivos da disciplina quanto ao conhecimento dos problemas da população pobre, à crítica sobre eles e sobre a insuficiência e ineficácia das políticas públicas e das restritas ações da sociedade civil, como pode ser observado em trechos dos depoimentos dos alunos, abaixo transcritos:

O trabalho permitiu que os conceitos de participação, comunidade e de movimentos sociais fossem contextualizados e compreendidos de forma significante. Um crescimento pessoal também se destaca, algo mudou depois da realização do trabalho. A luta, o sofrimento e as conquistas presentes no MST contribuíram para uma diferente visão sobre a vida, as pessoas e a política (Estudante 1, relatório 2002, segundo semestre).

Realizando a prática sobre o abastecimento alimentar no bairro em 2013, uma estudante escreveu que "Por ser a quarta visita ao bairro, me senti mais familiarizada com o local e os moradores, até reconhecendo alguns que sempre estão nas portas de casas" (Estudante 2, relatório 2013, primeiro semestre), o que sugere superação da insegurança inicial.

A presença de nutricionistas na assistência social chamou a atenção. Diante de um trabalho de recuperação de crianças e adolescentes em situação de rua, desenvolvido por uma fundação, uma estudante registrou em 2005, primeiro semestre: "Conferi a importância do nutricionista num projeto social, despertando em mim a vontade de trabalhar para uma melhor qualidade de vida das crianças e adolescentes" (Estudante 3, relatório 2005, primeiro semestre). No mesmo semestre, outra estudante assim se manifestou sobre seu contato com os moradores de um bairro popular: "O trabalho com a comunidade me tor- nou uma pessoa mais humana e sensível aos problemas vivenciados pela camada mais pobre" (Estudante 4, relatório 2005, primeiro semestre). Em 2006, uma estudante manifestou consciência e crítica social quando, conhecendo um projeto de uma ONG dirigido a idosos, relatou: "Aprendi que o idoso ainda é um cidadão e que o Estatuto do Idoso e a Política Nacional do Idoso estão muito longe da realidade" (Estudante 5, relatório 2006, primeiro semestre).

Em outro semestre, a questão habitacional focada sensibilizou os estudantes: "No bairro sobressai o tamanho pequeno da maioria das casas, o aspecto da construção sempre inacabada, com a expansão progressiva do imóvel" (Estudante 6, relatório 2008, segundo semestre). Ou ainda: "As ampliações das casas são para melhorar a moradia, para alugar e aumentar a renda insegura da ocupação informal ou para crescimento da familia, abrigar os filhos que casam e os parentes que vêm do interior" (Estudante 7, relatório 2008, segundo semestre). Uma aluna do semestre 2010 escreveu sobre sua inserção no bairro:

Este trabalho foi muito importante para mim, pelo fato de ter contato mais de perto com a realidade do subúrbio. o que antes eu só via na televisão, todas as quartas-feiras estavam ao meu redor. Pegando ônibus e indo a lugares antes totalmente distantes da minha realidade. Conheci famílias que vivem com muito pouco [...] (Estudante 8, relatório 2010, segundo semestre).

A integração da disciplina com projetos de extensão da universidade deu-se em três oportunidades. Inicialmente, mediante uma parceria entre a Prefeitura e uma empresa pública da área de Desenvolvimento Metropolitano, num Projeto de Educação Sanitária em bairros, entre 1987 e 1988, durante três semestres. Os bairros receberam investimentos em obras de saneamento, sistema viário e urbanização, além de melhoria nos serviços de abastecimento de água e limpeza pública. A universidade, através de equipe de pro- 
fessores e estudantes da área de saúde e engenharia sanitária, desenvolveu ações educativas nas escolas e espaços comunitários. Foi um projeto inovador em desenvolvimento urbano, na medida em que promoveu a integração simultânea entre a implantação de obras e serviços e a educação comunitária.

Entre 1996 e 2000, a prática de DCC esteve vinculada a um projeto de integração entre a universidade (envolvendo vários cursos da área da saúde), os serviços de saúde e a comunidade, com financiamento internacional. A participação do Curso de Nutrição se deu com o subprojeto "Combate à violência na escola". Foram cinco anos exercitando, dentro da universidade, o diálogo com uma equipe (professores, estudantes, profissionais de saúde e líderes comunitários) comprometida com mesmo objetivo: promover o aperfeiçoamento do ensino para os profissionais de saúde, através do desenvolvimento de modelos assistenciais e acadêmicos inovadores, contando com a participação ativa das comunidades e da rede pública de serviços de saúde. Enquanto intervenção, o projeto possibilitou a realização de atividades educativas, pelos universitários, em escolas públicas de educação básica. Ao lidar diretamente com os problemas sociais, os estudantes de Nutrição se imbuíram da responsabilidade cívica, revelando atitudes e habilidades dificilmente demonstráveis em sala de aula. A avaliação da experiência pelos universitários foi muito positiva, aliada ao sentimento de orgulho por estarem contribuindo para a prevenção da violência, ainda que modestamente ${ }^{18,19}$.

Outra experiência foi realizada em um bairro popular, de alta densidade populacional, no âmbito do Projeto Pró-Saúde, uma parceria entre os Ministérios da Saúde e Educação e realizado em vários centros brasileiros por universidades públicas. Durante 2010 e 2011 os estudantes fizeram suas práticas pesquisando sobre as condições de vida da população, enfatizando o abastecimento alimentar, atividade associada com um projeto de pesquisa sobre Segurança Alimentar.

\section{CONSIDERAÇÕ ES FINAIS}

A experiência foi analisada com os mesmos critérios que nortearam o trabalho acadêmico desenvolvido na disciplina, a saber: reconhecimento da sua natureza científica; clareza na definição do problema; análise orientada no diálogo entre teoria e prática; síntese conclusiva calcada na reflexão crítica valorativa, tanto ética quanto ideológica. Isso porque se adotou a premissa de que a formação do estudante requer competência técnico-científica no campo específico e domínios conexos, além comprometimento com os ideais de justiça social. A perspectiva dos autores e da disciplina aqui focada considera necessária não só a capacidade do estudante de discernir intelectualmente frente aos determinantes e condicionantes da relação alimentação-saúde-sociedade, mas também o desafio de tornar-se um cidadão crítico e socialmente responsável frente aos distintos segmentos sociais e à realidade observada e estudada.

Ao longo de mais de 30 anos da experiência pedagógica do DCC, foram estudados os mais importantes programas de desenvolvimento comunitário; as políticas públicas com projetos setoriais dirigidos à população de baixa renda; a legislação que institui e normatiza tais políticas; os movimentos sociais, particularmente aqueles movidos por grupos e classes populares; o associativismo comunitário; as instituições humanitárias tradicionais, como as fundações e igrejas de vários credos; os projetos de ONG de distintas naturezas; as ações de responsabilidade social de grandes empresas privadas voltadas às comunidades carentes.

Mesmo tendo em conta a lentidão formal das mudanças curriculares na universidade, na prática, a disciplina foi sendo modificada pela própria força da dinâmica social.

Ainda que vivenciando dificuldades operacionais na realização das práticas em comunidade, para muitos estudantes a experiência foi o primeiro contato com a pobreza, a desigualdade e a exclusão, assim como com os limites da ação 
pública no atendimento às demandas sociais, com alguma efetividade.

Ao longo dessa experiência docente em DCC, pôde-se observar que persiste na formação do nutricionista, ou entre aqueles envolvidos nesse processo, falta de clareza quanto aos conteúdos em Ciências Sociais e Econômicas, imprescindíveis para compor o currículo do Curso de Nutrição. Faltam às propostas curriculares o adequado diagnóstico da situação, bem como uma busca mais criteriosa dos objetivos e justificativa dos conteúdos sociais na formação dos nutricionistas.

Ainda pela experiência de DCC, avalia-se que, apesar das múltiplas dificuldades em manter o trabalho de campo, ao nutricionista cabe aprender sobre comunidades, considerando tanto o seu processo de construção histórico-social quanto o fato de serem elas o lugar onde os problemas alimentares e nutricionais se formam e são compartilhados - portanto, onde deve estar a ação pública que objetiva reduzir os problemas. Enfim, mesmo que a disciplina DC deixe de existir na formação do nutricionista com a denominação original - que faz parte do repertório semântico de um tempo passado -, os conteúdos e experiências permanecem sendo relevantes e podem ser incorporados em outras disciplinas.

\section{REFERÊ N CIAS}

1. Santos SMC. Nutricionista \& sociedade brasileira: elementos para abrodagem histórico-social da profissão [dissertação]. Salvador: Universidade Federal da Bahia; 1988.

2. Pinto JBG. Reflexões sobre desenvolvimento social, trabalho com grupos e ação comunitária. Recife: Sudene; 1980.

3. Brasil. Ministério do Interior. Diretrizes e formas de implementação do programa de desenvolvimento de comunidade. Brasília: Minter; 1979.

4. Bosi MLM. A face oculta da nutrição: ciência e ideologia. Rio de Janeiro: Espaço e Tempo; 1988.

5. Canesqui AM, Garcia RWD, Organizador. Ciências sociais e humanas nos cursos de nutrição. In: An- tropologia e nutrição: um diálogo possível. Coleção Antropologia e Saúde. Rio de Janeiro: Fiocruz; 2005. p.244-74.

6. Brasil. Ministério da Educação. Conselho Nacional de Educação. Resolução CNE/CES nº 5, de 7 de novembro de 2001. Institui diretrizes curriculares nacionais do curso de graduação em nutrição. Diário Oficial [da] União. 2001 nov. 9; Seção 1. p.39.

7. Soares NT, Aguiar AC. Diretrizes curriculares nacionais para os cursos de Nutrição: avanços, lacunas, ambiguidades e perspectivas. Rev Nutr. 2010 [acesso 2014 jun 8]; 23(5):895-905. Disponível em: <http://www.scielo.br/pdf/rn/v23n5/a19v23n5. pdf>. doi: 10.1590/S1415-52732010000500019

8. Jacobi P. Movimentos sociais e políticas públicas. São Paulo: Cortez; 1990.

9. Doimo AM. A vez e a voz do popular: movimentos sociais e participação política no Brasil pós-70. Rio de Janeiro: Relume; 1995.

10. Santos SMC. Fome de cidadania: a Comunidade Solidária e a Participação em Programas de Nutrição em Municípios Baianos [tese]. Salvador: Universidade Federal da Bahia; 2001.

11. Oliveira, N. Participação de líderes comunitários nas eleições municipais. Veracidade. 2009; 5(8):47-58.

12. Ferreira VA, Magalhães R. Nutrição e promoção da saúde: perspectivas atuais. Cad Saúde Pública. 2007; 23(7):1674-81.

13. Neves MAB, Spinelli MA. Integração ensino-serviços de saúde: o internato rural médico da Universidade Federal de Mato Grosso. Trab Educ Saúde. 2008, 6(2):341-66.

14. Santos M. O espaço do cidadão. São Paulo: Nobel; 1987.

15. Bosi MLM, Trabalho e subjetividade: cargas e sofrimento na prática da nutrição social. Rev Nutr. 2000; 13(2):107-15. doi: 10.1590/S1415-5273200 0000200005

16. Oliveira, N. Conhecendo um bairro popular: universitários em campo. Veracidade. 2011; 7(11)59-71.

17. Gidden A. Sociología. Madrid: Alianza Editorial; 1993.

18. Oliveira N. Refletindo sobre um projeto de extensão universitária. UNISaber. 2002; 2(2):37-60.

19. Oliveira N. Combate à violência na escola: relato de uma experiência. Tema Livre. 2002; 5(58):4-5.

Recebido em: 11/6/2014

Versão final em: 31/10/2014

Aprovado em: 3/11/2014 
